\title{
SHEEHAN'S SYNDROME- POSTPARTUM ADENOHYPOPHYSEAL INSUFFICIENCY- A CASE REPORT
}

\author{
Hemant R. Gupta1, Minal Ashok Meshram², Utina Kichu³, Anish Kamble4
}

${ }_{1}^{1}$ Associate Professor and HOD, Department of Medicine, Grant Government Medial College, Mumbai, Maharashtra, India.

2Junior Resident, Department of Medicine, Grant Government Medial College, Mumbai, Maharashtra, India.

3 Junior Resident, Department of Medicine, Grant Government Medial College, Mumbai, Maharashtra, India.

${ }^{4}$ Senior Resident, Department of Medicine, Grant Government Medial College, Mumbai, Maharashtra, India.

HOW TO CITE THIS ARTICLE: Gupta HR, Meshram MA, Kichu U, et al. Sheehan's syndrome- postpartum adenohypophyseal insufficiency- a case report. J. Evolution Med. Dent. Sci. 2018;7(40):4401-4402, DOI: 10.14260/jemds/2018/982

\section{PRESENTATION OF CASE}

35-year female presented to the casualty with drowsiness and inability to move limbs/inability to speak immediately after a seizure episode that had occurred 5 minutess prior to her presentation, on the way from the ambulance to the casualty. Patients relatives gave history of the patient having fever associated with chills, headache, drowsiness, vomiting episodes and had not taken any fluids or solid food since 2 days.

On examination the patient was drowsy, haemodynamically stable, BP 106/70 mmHg, taken over right arm in supine position, pulse rate of 72 beats $/ \mathrm{min}$.

CNS examination revealed drowsiness/confusion with inability to follow simple verbal commands. B/L pupils normal sized, reactive to light. Upper and lower limb DTR present.

Cardiovascular, respiratory and abdominal examination did not reveal any significant abnormality.

Patient's blood sugar level was checked on the spot using a glucometer which revealed very low/nonrecordable blood sugar level, intravenous access was immediately established, and patient was administered $25 \%$ dextrose infusion with improvement in her sensorium 2-3 mins after administration.

Other possible causes of seizure were worked up.

Serum electrolytes, calcium, magnesium were within normal limits. Fundoscopy did not reveal any evidence of papilloedema. CECT brain did not reveal any significant abnormality.

ECG revealed sinus rhythm with no ST-T wave changes thus ruling out syncope due to arrhythmias or Brugada/Stoke Adams/inferior wall myocardial infarction given the clinical scenario of sudden collapse.

CSF examination was within normal limits except for mildly elevated proteins.

Patient gave history of amenorrhoea since 9 years immediately after her fourth and last child was born, with inability to nurse her last child after delivery.

Previous three pregnancies remained absolutely normal with no evidence of lactational failure. Also, history of extensive blood loss was elicited immediately after her last delivery followed by 3-4 blood transfusions suggesting catastrophic post-partum haemorrhage.

'Financial or Other Competing Interest': None.

Submission 17-08-2018, Peer Review 15-09-2018,

Acceptance 21-09-2018, Published 01-10-2018.

Corresponding Author:

Dr. Hemant R. Gupta,

\#203, Erica Dosti Acres Complex,

Near Antop Hil Bus Depot, Wadalaced,

Anicphill, Mumbai-400037,

Maharashtra, India.

E-mail: drhemantgupta@hotmail.com

DOI: $10.14260 /$ jemds $/ 2018 / 982$
Patients skin was dry, coarse with facial and periorbital puffiness, hoarseness of voice. In view of these findings and history of amenorrhea, patient's thyroid function was evaluated which revealed low $\mathrm{T} 3$ and $\mathrm{T} 4$ with lower normal levels of TSH. (T3- $35.69 \mathrm{ng} / \mathrm{dL}, \mathrm{T} 4-0.85 \mathrm{ug} / \mathrm{dL}$, TSH 1.39 $\mathrm{uIU} / \mathrm{mL}$ ) suggestive of central hypothyroidism. Patients hormonal panel revealed low cortisol (1.35 ug/dL), low prolactin (3.91 ng/mL) low FSH (2.8 mIU/mL), low LH (0.71 $\mathrm{mIU} / \mathrm{mL})$, low $\mathrm{GH}(0.05 \mathrm{ng} / \mathrm{mL})$, low ACTH suggesting hypopituitarism.

${ }^{1}$ Sheehan's syndrome can present with complete or partial pituitary insufficiency resulting from severe post-partum haemorrhage. The pituitary gland, owing to its enlargement during pregnancy secondary to high oestrogen levels and hypervascularity, remains vulnerable to arterial pressure changes and prone to haemorrhage/infarction following hypovolaemic shock encountered during post-partum haemorrhage. ${ }^{2}$ The presentation ranges from sudden catastrophic event of hypovolaemic shock followed by pituitary necrosis to gradual onset of partial to complete pituitary insufficiency over months to years. Here is the case of a patient presenting with central hypopituitarism 9 yrs. after the acute episode of post-partum haemorrhage.

3Sheehan's syndrome, first described by Harold Sheehan in 1937 , is characterised by pituitary necrosis characteristically after post-partum haemorrhage. It includes features of central hypothyroidism including peri-orbital puffiness, hoarseness of voice, dry coarse yellowed skin, sparse hair and features like dizziness, hypotension, hypoglycaemia, vomiting, asthenia, weight loss, signifying low cortisol production with ovarian failure characterised by lactational failure, amenorrhoea, regression of secondary sexual characters. ${ }^{4}$ For signs and symptoms of central hypopituitarism to appear, atleast seventy five percent of the gland should have undergone destruction/necrosis.

\section{DIFFERENTIAL DIAGNOSIS}

- Sheehan's Syndrome: Postpartum pituitary apoplexy due to obstetric haemorrhage.

- Lymphocytic Hypophysitis.

- Haemorrhage in a Pre-Existing Pituitary Adenoma.

- Infarction in a Pre-Existing Pituitary Adenoma.

- Meningitis.

- Cerebral Venous Sinus Thrombosis.

\section{CLINICAL DIAGNOSIS}

Central Hypopituitarism secondary to Pituitary Necrosis in Sheehan's Syndrome 


\section{PATHOLOGICAL DISCUSSION 5}

The pituitary gland is a highly vascular structure with the peculiarity being the hypothalamo-hypophyseal portal system. It is hence prone to necrosis from vascular injury following sudden hypotension/sudden pressure change as may occur in case of Sheehan's syndrome after a massive postpartum haemorrhage.

${ }^{6}$ Other causes of hypopituitarism include pituitary and parapituitary tumours like craniopharyngioma, meningioma, irradiation, infiltration- sarcoidosis, lymphocytic hypophysitis, tuberculosis, haemochromatosis, histiocytosis, trauma.

7 The clinical presentation depends on the type and degree of hormonal deficit.

${ }^{8}$ Empty sella syndrome refers to an enlarged pituitary fossa due to arachnoid herniation through congenital diaphragmatic defect or secondary to surgery, radiotherapy or pituitary infarction.

\section{Following are the MRI Images of the above Patient}

Sagittal view shows a partially atrophic pituitary gland with thin rim of tissue with herniation of CSF into the sella.

The transverse view shows CSF as bright/white. It has occupied the empty sella just above the optic chiasm.

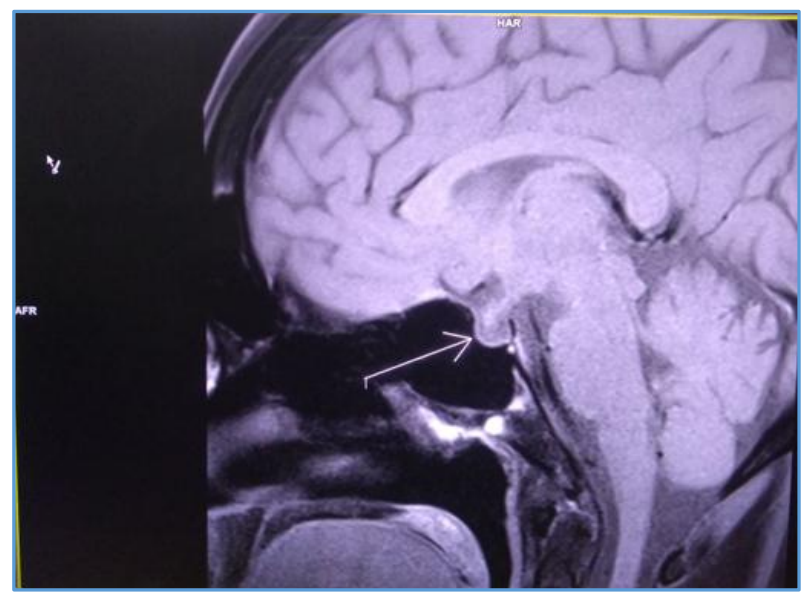

Figure 1

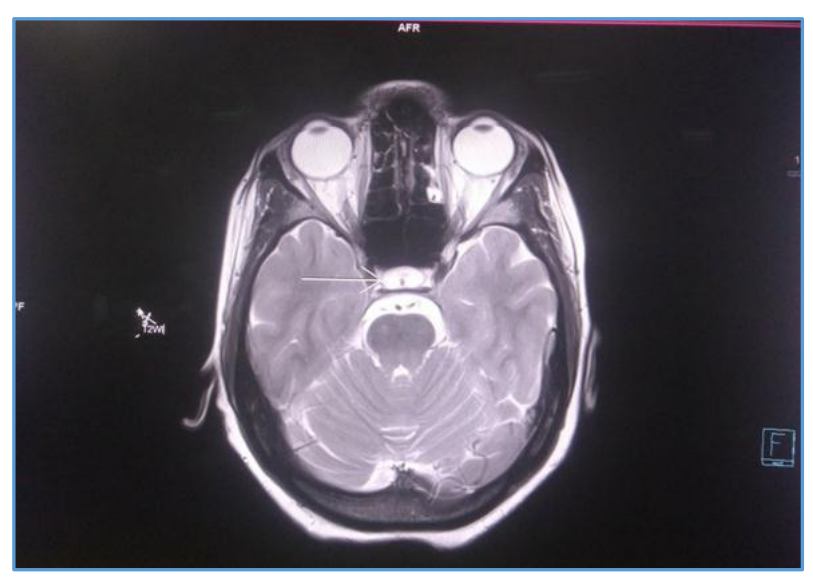

Figure 2

MRI brain confirmed pituitary atrophy with partial empty sella with secondary herniation of optic chiasm through diaphragm sellae thus confirming Sheehan's syndrome as the diagnosis.

The diagnosis is confirmed by MRI brain imaging on T1 and $\mathrm{T} 2$ weighted images showing empty sella with herniation of CSF.

\section{DISCUSSION ON MANAGEMENT}

${ }^{9}$ Hormonal replacement remains the mainstay of management in Sheehan's syndrome.

In our case the patient was initiated on intravenous hydrocortisone, its dose was gradually tapered, and the patient was shifted to oral prednisolone at $5 \mathrm{mg}$ per day/stress dose.

Also, after primarily administering hydrocortisone and replenishing the cortisol levels, patient was started on oral thyroxine beginning at a dose of 25 mcg daily and gradually increasing it according to biochemical and clinical response.

${ }^{10}$ The patient was also initiated on cyclical hormonal replacement with Tab. Progynova (Estradiol) $2 \mathrm{mg}$ for 21 days followed by Tab. Devery (Medroxyprogesterone) $10 \mathrm{mg}$ for day 21 to day 30 of the month in a cyclical pattern.

This patient did not present with persistent hyponatremia so intranasal desmopressin was not initiated.

\section{FINAL DIAGNOSIS}

Sheehan's Syndrome

\section{REFERENCES}

[1] Sheehan HL. Post-partum necrosis of the anterior pituitary. J Pathol Bacteriol 1937;45:189.

[2] Grimes HG, Brooks MH. Pregnancy in Sheehan's syndrome. Report of a case and review. Obstet Gynecol Surv 1980;35(8):481-8.

[3] Merger R, Levy J, Melchior J. Précis d'obstétrique. 4th édn. Paris: Masson 1974: p. 321-31.

[4] Huang YY, Ting MK, HSH BRS, et al. Demonstration of reserved anterior pituitary function among the patients with amenorrhea after postpartum hemorrhage. Gynecol Endocrinol 2000;14(2):99-104.

[5] Perraudin V, Lefebvre H, Kuhn JM. Insuffisance antéhypophysaire. Encycl Méd chi (Paris), Endocrinologie - Nutrition 10-019-A-10. 1992: p. 1-12.

[6] Jialal I, Naidoo C, Norman RJ, et al. Pituitary function in Sheehan's syndrome. Obstet Gynecol 1984;63(1):15-9.

[7] Kelestimur F. Sheehan's syndrome. Pitutary 2003;6(4):181-8.

[8] Sheehan HL. Simmonds disease due to postpartum necrosis of the anterior pituitary following postpartum haemorrhage. Q J Med 1939;32:277-309.

[9] Assan R. Urgences métaboliques et endocriniennes. In: Kleinknecht D, edr. Principes de réanimation médicales. $3^{\text {rd }}$ édn. Paris: Flammarion Médecine Sciences 1984: p. 292-326.

[10] Molitch ME. Pituitary diseases in pregnancy. Semin Perinatol 1998;22(6):457-70. 